\title{
Visual-Procedural Memory Consolidation during Sleep Blocked by Glutamatergic Receptor Antagonists
}

\author{
Steffen Gais, Björn Rasch, Ullrich Wagner, and Jan Born \\ Department of Neuroendocrinology, University of Lübeck, 23538 Lübeck, Germany
}

Visual cortex plasticity is enhanced by sleep. It is hypothesized that a reactivation of glutamatergic synapses is essential for this form of plasticity to occur after learning. To test this hypothesis, human subjects practiced a visual texture discrimination skill known to require post-training sleep for improvements to occur. During sleep, glutamatergic transmission was inhibited by administration of the two glutamate antagonists, caroverine and ketamine, targeting the ionotropic NMDA and AMPA receptors. Both substances given during consolidation sleep in a placebo controlled crossover design were able to prevent improvement of the skill measured the next morning. An off-line activation of glutamatergic synapses therefore seems to play a critical part in the consolidation of plastic changes in the visual cortex.

Key words: sleep; memory consolidation; skill learning; visual discrimination; glutamate receptor; human

\section{Introduction}

The role of sleep for the development of stable, experiencedependent changes in the visual cortex has been described previously in a number of studies (Karni and Sagi, 1993; Karni et al., 1994; Gais et al., 2000; Stickgold et al., 2000). Practice alone is not sufficient to induce improvement in visual texture discrimination performance, but long-lasting enhancements in performance occur only if practice is followed by sleep. Whereas the behavioral side of this effect is well examined, the underlying mechanisms are still largely obscure. However, visual discrimination learning has the advantage of being a very basic form of memory. It is known that the learning-dependent improvements in visual texture discrimination are monocular and restricted to the retinal position that was trained (Karni and Sagi, 1991). Consequently, learning related changes must be confined to those early areas of the primary visual cortex, where processing of visual input is still monocular and retinotopic. Accordingly, after learning, stronger brain activity responses to learned stimuli have been observed, restricted to the specific retinotopic areas of the primary visual cortex (Schwartz et al., 2002). It can be assumed that only the receptive fields of specific, orientation-sensitive neurons in the primary visual cortex are more finely tuned as a result of the learning process, possibly restricted to those synapses that were involved in previous task practice (Schoups et al., 2001).

A major hypothesis in sleep and memory research is that those networks that were involved in previous daytime experience are reactivated during sleep (Buzsáki, 1998; Maquet, 2001; Pennartz et al., 2002; Rasch et al., 2007). This reactivation hypothesis has

\footnotetext{
Received Dec. 5, 2007; revised March 11, 2008; accepted April 4, 2008.

This work was supported by Deutsche Forschungsgemeinschaft SFB 654.

Correspondence should be addressed to either Jan Born or Steffen Gais, Department of Neuroendocrinology, University of Lübeck, Ratzeburger Allee 160, 23538 Lübeck, Germany. E-mail: born@kfg.uni-luebeck.de or gais@kfg.uni-luebeck.de.

D0I:10.1523/JNEUROSCI.5374-07.2008

Copyright $\odot 2008$ Society for Neuroscience $\quad$ 0270-6474/08/285513-06\$15.00/0
}

received considerable support in animal research with regard to the declarative, hippocampal memory system (Wilson and McNaughton, 1994; Nadasdy et al., 1999), but also with regard to other memory systems (Dave and Margoliash, 2000; Ribeiro et al., 2004). In humans, functional neuroimaging studies demonstrate a reactivation of brain regions during postlearning sleep (Maquet et al., 2000), and coherence of electroencephalographical activity increases during sleep after an intensive learning period (Huber et al., 2004; Mölle et al., 2004). Reactivation might improve memory by two routes. It might allow the off-line transfer of information between different brain networks (systems consolidation) and it might strengthen individual synapses involved in storing a memory trace by providing additional "practice" to previously tagged synapses (synaptic consolidation) (Dudai, 2004). In the case of visual texture discrimination learning, the latter is probably of higher importance because of the restriction of this task to the primary visual cortex.

Glutamate is one of the main excitatory neurotransmitters in the visual cortex (Baughman and Gilbert, 1980). It has been strongly implicated in synaptic plasticity and learning (Artola and Singer, 1987; Miller et al., 1989; Kirkwood et al., 1996). Both AMPA and NMDA glutamate receptors can be found in the visual cortex (Kumar et al., 1994; Rivadulla et al., 2001) and both play roles in synaptic potentiation (Bear, 1996; Rumpel et al., 1998; Quinlan et al., 1999; Boroojerdi et al., 2001; Watt et al., 2004). AMPA receptors are thought to contribute to information transmission between neurons, whereas NMDA receptors are mainly considered to be coincidence detectors that activate after multiple previous depolarizations (Malenka and Nicoll, 1999). The NMDA receptor activation subsequently leads to a longlasting increase in synaptic AMPA receptor availability and synaptic potentiation (Artola and Singer, 1987; Rumpel et al., 1998). However, NMDA receptors in the visual cortex are also involved in information transmission (Fox et al., 1989; Daw et al., 1993; Rivadulla et al., 2001). 
Memory undergoes a postlearning period of consolidation. If this process is solely dependent on activation during practice, with later maturation depending only on intracellular signaling cascades, it should be independent of intervening synaptic activity. If, however, consolidation depends on reactivation of memory traces, then a temporary blockade of glutamate receptors after learning could prevent post-training memory enhancement (Ribeiro et al., 2004; Foster and Wilson, 2006; Peigneux et al., 2006). Here, we tested the hypothesis that during sleep memory traces are reactivated in the visual cortex in a glutamatedependent process. To achieve this, we temporarily blocked glutamatergic activity in healthy human subjects with two different glutamatergic antagonists (ketamine or caroverine) in a placebo controlled crossover experimental design. The substances were administered in a way that they were active only during a period of $6 \mathrm{~h}$ during postlearning sleep and affected neither learning nor retrieval.

\section{Materials and Methods}

Subjects and general procedure. Two groups of subjects $(n=11$ for caroverine; $n=15$ for ketamine) participated in the experiments. Subjects were nonsmoking males with normal or corrected to normal vision (age, $24.9 \pm 0.8$; mean \pm SEM). They were screened for acute and chronic diseases, mental disorders, and drug addictions, and they were not taking any medication at the time of the experiments. All of them were normal sleepers (7-9 h per night) with no major disruptions of the sleep-wake cycle during the 6 weeks before the experiments. Subjects were not allowed to take in caffeine and alcohol or to sleep during daytime before experimental nights.

Before the experiments, subjects were accustomed to sleeping under laboratory conditions. Each subject participated in two experimental sessions (substance and placebo), which followed a double-blind, randomized, and balanced crossover design. Sessions were spaced at least 4 weeks apart. On the days of the experiments, subjects learned the visual texture discrimination task (VDT) at 10:00 P.M. At 11:00 P.M. they went to bed and lights were turned off. Substance administration started at sleep onset, defined by the first occurrence of sleep stage 2. Subjects were awakened $8 \mathrm{~h}$ after sleep onset. Retesting took place $30 \mathrm{~min}$ after awakening (see Fig. 1b). Sleep was recorded polysomnographically and scored according to standard criteria. Aside from retrieval testing, testing after sleep included an assessment of subjective tiredness by questionnaire as well as an interview regarding side effects of substance administration. Statistics generally relied on an ANOVA with the two withinsubject factors pretest/post-test and substance/placebo. Experiments were approved by the Ethics Committee of the University of Lübeck.

Behavioral testing. All tests took place in a soundproof, dark chamber. Subjects in the main experiments had to learn a VDT, which required them to discriminate between a small horizontal or vertical target stimulus, presented briefly in the periphery of the visual field (Karni and Sagi, 1991; Gais et al., 2000) (Fig. 1a). Each session consisted of 950 consecutive trials. Trials started when the subject pressed a key after a fixation cross was displayed. First, the screen went blank for 210-270 ms. Then, the target stimulus appeared for $10 \mathrm{~ms}$, followed by a blank screen, a mask for $100 \mathrm{~ms}$, and again a blank screen. The time between the stimulus and mask [stimulus-to-mask onset asynchrony (SOA)] was variable and successively reduced from 400 to $40 \mathrm{~ms}$ ( 50 trials each: 400, 300, 200, and 160 ms; 150 trials each: 140, 120, 100, 80, and $60 \mathrm{~ms}$ ). Under some conditions, mainly when task presentation uses sessions with unequal numbers of stimuli, learning in the VDT seems to take place also across periods of wakefulness (Karni and Sagi, 1993; Censor et al., 2006). Here, we used an experimental setup with a fixed number of stimuli that has consistently shown to require sleep for consolidation related improvements to occur (Gais et al., 2000; Stickgold et al., 2000).

Before the experiment proper, subjects practiced the task in the presence of the experimenter with 50 additional trials at an SOA of $400 \mathrm{~ms}$. The stimuli were $16^{\circ}$ of visual angle in size and consisted of a $19 \times 19$ field of horizontal bars $(17 \times 17 \mathrm{~cm})$ with a randomly rotated T- or L-shaped figure in the center. Bars were $0.6^{\circ}(6 \mathrm{~mm})$ long and $0.05^{\circ}(0.4 \mathrm{~mm})$ wide. Stimuli had an intensity of $2.25 \mathrm{~cd} / \mathrm{m}^{2}$, background intensity was 0.01 $\mathrm{cd} / \mathrm{m}^{2}$. The pop-out target was located at a distance of $3-5^{\circ}$ visual angle from the center and consisted of three oblique bars aligned either horizontally or vertically. The target was shown in the same quadrant of the visual field during learning and subsequent retrieval, but in different quadrants for the two experimental conditions, because learning in this task is restricted to the retinal position where the target appeared. After each trial the subject had to press one of two keys to indicate which letter had been presented in the center of the screen to ensure proper fixation, and whether the target was aligned horizontally or vertically. Errors on the fixation task were indicated instantly by a tone. All subjects met the criterion of $>90 \%$ correct responses in the T/L discrimination until at least 1 step below the discrimination threshold for the horizontal/vertical discrimination (on average, $98.1 \%$ correct in the block directly above threshold SOA for the horizontal/vertical task). Only trials with a correct response entered into the analysis, thus excluding all trials with an obvious lack of fixation, but leaving those trials with improper fixation where the subjects guessed the correct response (i.e., statistically half of the fixation errors were omitted from analysis). Because of the small number of fixation errors, these can be expected to have only a minor effect on the analysis. There was no time limit for giving the answer, and subjects were told to take breaks when needed. Performance was measured with reference to the per cent correct responses at a given SOA. Threshold SOA was calculated by interpolating the SOA with a recognition rate of $80 \%$. The detection threshold for fixation stimuli was also calculated using the same method. The procedure for retrieval testing was identical to that used during the learning session.

Substance administration and blood sampling. Thirty minutes before behavioral testing, two intravenous catheters were inserted into the subject's forearm for blood sampling and substance administration. Beginning with sleep onset, subjects received in the verum condition a slow, constant intravenous infusion of $50 \mathrm{ml}$ of isotonic saline solution with either $0.25 \mathrm{mg} / \mathrm{kg}$ body weight of S-ketamine (Ketanest S; Pfizer) or 80 $\mathrm{mg}$ of caroverine (Calmaverine; Taphlan) over $6 \mathrm{~h}$. Placebo was $50 \mathrm{ml}$ of isotonic saline solution. Both substances are acting predominantly as glutamate receptor antagonists. Ketamine is an NMDA receptor antagonist and has been used in high doses primarily for this action as local or general anesthetic. Previously, it has been proposed that ketamine might also bind to dopaminergic $\mathrm{D}_{2}$ receptors (Kapur and Seeman, 2002). The dosage of ketamine was chosen on the basis of previous literature as to avoid anesthetic effects while still retaining effects on memory function. Caroverine is primarily an AMPA receptor antagonist and, at higher doses, acts as an NMDA receptor antagonist (Oestreicher et al., 2002). At the smooth muscle, caroverine is also a B-type calcium-channel blocker (Ikeda et al., 1982). Because the plasma half-lives of ketamine (10-15 $\mathrm{min}$ ) and caroverine $(25 \mathrm{~min})$ are rather short, the glutamate receptor antagonists were constantly infused for $6 \mathrm{~h}$ during the night to maintain the minimal dose necessary for receptor inhibition. However, both antagonists can be assumed to be no longer effective at the time of retrieval because infusion was stopped $2 \mathrm{~h}$ before awakening and initial doses were low. To ensure that caroverine has no immediate effect on discrimination performance, we administered caroverine and placebo to a preliminary sample of six additional subjects during two nights according to an identical experimental schedule. In the morning, they performed on an untrained visual discrimination task. These data show no significant differences in detection performance between caroverine and placebo nights $(130 \pm 13 \mathrm{~ms}$ for caroverine vs $138 \pm 17 \mathrm{~ms}$ for placebo). Experiments were double blind. Unblinding took place only during statistical analysis when data were assigned to the respective conditions.

To control for neuroendocrine side effects, blood was collected during sleep via thin plastic tubes from an adjacent room without disturbing subjects' sleep. Blood was sampled before and after test performance and hourly, beginning $30 \mathrm{~min}$ after sleep onset. Blood was immediately centrifuged and frozen at $-20^{\circ} \mathrm{C}$ until assay. Cortisol was determined from serum by enzyme immunoassay (DSL-10-2000 Active Cortisol; Diagnostic Systems Laboratories). Blood norepinephrine levels were determined from EDTA-plasma by standard high-performance liquid chromatography (Waters) with electrochemical detection. 
a
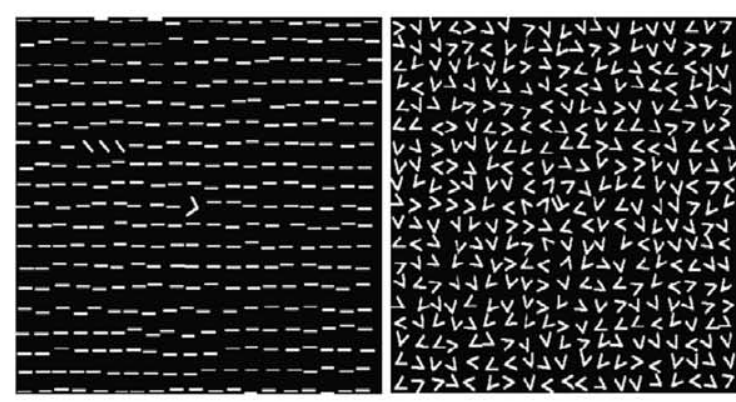

b

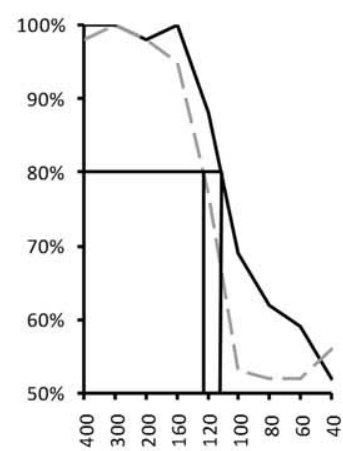

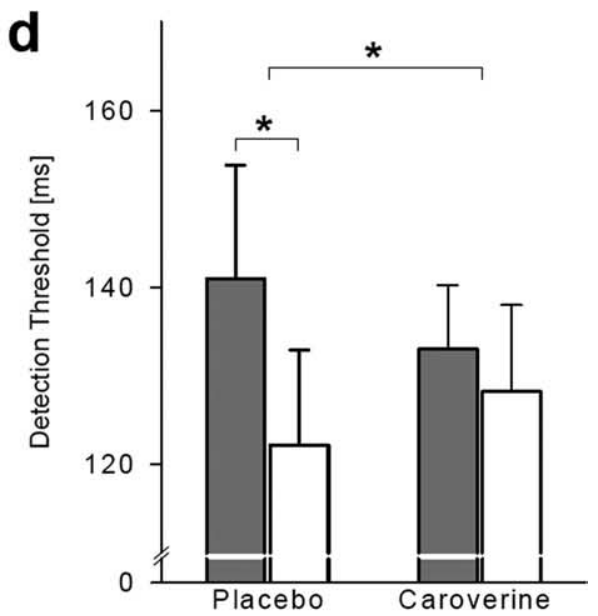

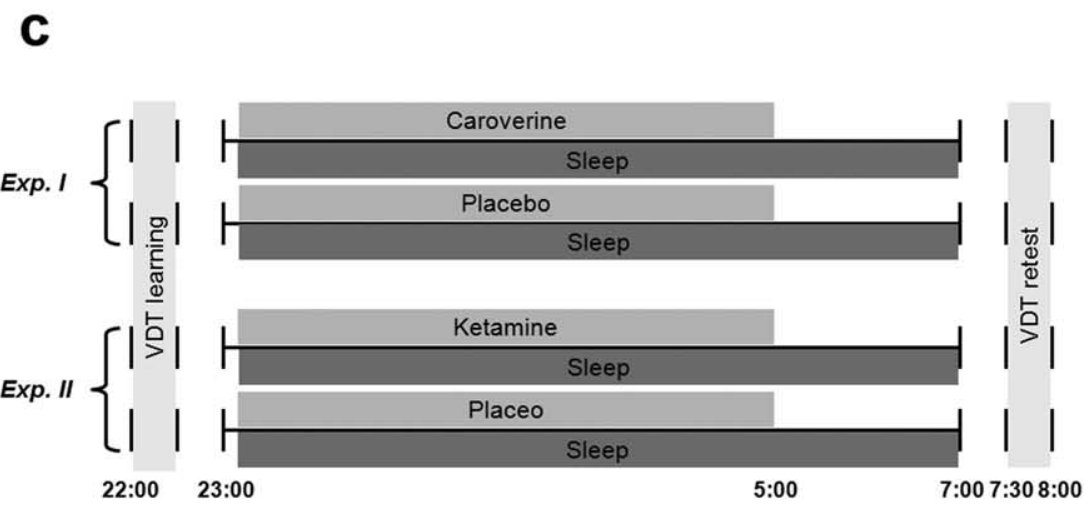

Figure 1. VDT. $\boldsymbol{a}$, Task: stimulus (left) and mask (right) as used in the visual discrimination task. The letter in the center of the stimulus serves to ensure proper fixation. The target (oblique bars) is thus perceived only peripherally. It appears always in the same quadrant, but quadrants were changed between substance conditions. The subject is required to discriminate whether the bars are aligned horizontally (as in this example) or vertically. The mask follows the stimulus after an SOA of 20-300 ms to extinguish afterimages of the stimulus. $\boldsymbol{b}$, Illustration of how actual detection thresholds were determined. c, Experimental design: two different groups of subjects (Exp. 1, Exp. 2) each participated in two conditions, receiving substance (caroverine, $80 \mathrm{mg}$, or ketamine, 0.6 $\mathrm{mg} / \mathrm{kg}$ body weight) and placebo according to a balanced crossover design. Substance infusion started at sleep onset and continued for $6 \mathrm{~h} . \boldsymbol{d}, \mathrm{VDT}$ performance: mean ( \pm SEM) detection thresholds of subjects during pretest before sleep (gray bars) and post-test after sleep (white bars). During sleep between tests subjects received placebo, caroverine (top), or ketamine (bottom). In both placebo conditions, subjects showed significantly lower discrimination thresholds and, thus, a better performance, at post-test after sleep. In both substance conditions, no such increase in performance through learning was achieved. Pretest/post-test by placebo/substance interactions are significant. ${ }^{*} p<0.05$.

\section{Results}

In a first experiment, we administered the AMPA receptor antagonist caroverine during sleep after subjects had practiced a VDT, which required subjects to determine the direction of a target stimulus displayed only for a very brief interval (Gais et al., 2000) (Fig. 1a,b). When performance was measured on the next day, subjects showed no significant improvement in discrimination speed between pretest and post-test when they received caroverine during previous sleep $\left(t_{(10)}=0.7 ; p=\right.$ $0.50)$ (Fig. 1c), whereas they showed the expected improvement after a placebo night $\left(t_{(10)}=2.9 ; p=0.02\right)$. The overnight improvement in terms of a decrease in detection threshold averaged $-18.4 \pm 6.3 \mathrm{~ms}$ after placebo, but only $-4.8 \pm$ $6.7 \mathrm{~ms}$ after caroverine. Comparing both conditions confirmed that these improvements differ significantly [measurement (pretest/post-test) $\times$ substance (caroverine/placebo): $\left.F_{(1,10)}=5.0 ; p=0.05\right]$.

Sleep was recorded during the night after task practice. Sleep-stage distribution and total sleep time were comparable between caroverine and placebo conditions (Table 1). Mea- sures of cortisol and norepinephrine were also taken throughout the night. Total secretion [area under curve (AUC)], minimum (Min), and maximum (Max) values did not differ between both conditions [placebo vs caroverine, $p>0.20$ for all comparisons; cortisol: AUC (in $\mu \mathrm{g}^{\star} \mathrm{h} / \mathrm{dl}$ ) $71.9 \pm 7.9$ vs $68.2 \pm 7.5$, Min (in $\mu \mathrm{g} / \mathrm{dl}$ ) $1.7 \pm 0.5$ vs $1.7 \pm 0.4$, Max (in $\mu \mathrm{g} / \mathrm{dl}) 19.6 \pm 1.0$ vs $19.8 \pm 1.0$; norepinephrine: AUC (in $\left.\mathrm{pg}^{\star} \mathrm{h} / \mathrm{ml}\right) 1302 \pm 114$ vs $1284 \pm 88$, Min (in pg/ml) $95 \pm 9 \mathrm{vs}$ $86 \pm 11, \operatorname{Max}($ in pg/ml) $310 \pm 34$ vs $329 \pm 29$ ].

In the second experiment, the NMDA receptor antagonist ketamine was administered according to the same experimental design used in the first experiment. Healthy subjects received ketamine during sleep after practice of the VDT. The results showed a pattern similar to that of caroverine administration. There was no significant improvement in performance between pretest and post-test if subjects received ketamine $\left(t_{(14)}=-0.38 ; p=0.71\right)$ (Fig. $\left.1 c\right)$. When subjects received placebo, they showed the known postlearning amelioration of discrimination performance $\left(t_{(14)}=2.2 ; p=\right.$ $0.04)$. The decrease in detection thresholds with reference to 
Table 1. Sleep stage distribution and total sleep time during experimental and control conditions of the experiments testing visual texture discrimination learning

\begin{tabular}{|c|c|c|c|c|c|c|c|}
\hline & $\%$ Wake & $\%$ S1 & $\%$ S2 & $\% \mathrm{S3}$ & $\%$ S4 & \% REM & TST \\
\hline Placebo & $4.1 \pm 2.4$ & $10.6 \pm 2.6$ & $50.7 \pm 2.5$ & $11.0 \pm 1.7$ & $4.2 \pm 0.8$ & $17.6 \pm 1.7$ & $478.1 \pm 2.3$ \\
\hline Caroverine & $4.3 \pm 2.1$ & $10.7 \pm 2.8$ & $51.7 \pm 2.3$ & $9.6 \pm 1.4$ & $3.8 \pm 0.7$ & $18.0 \pm 1.8$ & $481.2 \pm 2.3$ \\
\hline Placebo & $2.9 \pm 1.0$ & $12.7 \pm 2.6$ & $50.2 \pm 1.8$ & $10.0 \pm 1.2$ & $4.2 \pm 1.1$ & $19.8 \pm 1.0$ & $434.7 \pm 5.4$ \\
\hline Ketamine & $4.3 \pm 1.7$ & $12.5 \pm 3.6$ & $48.5 \pm 2.8$ & $10.4 \pm 0.8$ & $4.8 \pm 1.1$ & $18.5 \pm 1.6$ & $417.6 \pm 16.1$ \\
\hline
\end{tabular}

TST, Total sleep time; REM, rapid eye movement; $S 1-S 4$, stages 1-4. All comparisons between placebo and substance (caroverine, ketamine) are nonsignificant (paired $t$ test, $p>0.20$ ).

training before sleep averaged $-14.7 \pm 6.6 \mathrm{~ms}$ after placebo, whereas after ketamine detection thresholds slightly increased by $+1.5 \pm 4.3 \mathrm{~ms}$ on average. Comparing both conditions revealed a significant measurement by substance interaction $\left(F_{(1,14)}=4.9 ; p=0.04\right)$.

Sleep was not affected by ketamine (Table 1). Total secretion, minimum, and maximum values of cortisol and norepinephrine did not show differences between conditions [placebo vs ketamine, $p>0.55$ for all comparisons; cortisol: AUC (in $\mu \mathrm{g}^{\star} \mathrm{h} / \mathrm{dl}$ ) $70.2 \pm 4.8$ vs $72.7 \pm 3.6$, Min (in $\mu \mathrm{g} / \mathrm{dl}$ ) $1.4 \pm 0.1$ vs $1.4 \pm 0.1$, $\operatorname{Max}$ (in $\mu \mathrm{g} / \mathrm{dl}$ ) $19.3 \pm 0.6$ vs $18.8 \pm 0.7$; norepinephrine: AUC (in pg*h/ml) $1486 \pm 121$ vs $1497 \pm 112$, Min (in pg/ml) $85 \pm 13$ vs $84 \pm 6$, Max (in pg/ml) $529 \pm 49$ vs $492 \pm 51$ ].

In both experiments, no significant differences between placebo and substance conditions were found for subjective ratings of tiredness and concentration $(p>0.55)$. The detection threshold for the fixation stimuli during VDT performance also did not differ between placebo and substance (placebo vs ketamine, $67.2 \pm 6.4 \mathrm{~ms}$ vs $69.4 \pm 6.8 \mathrm{~ms}, p>0.49$; placebo vs caroverine, $74.3 \pm 5.3 \mathrm{~ms}$ vs $72.3 \pm 4.1 \mathrm{~ms}, p>0.59$ ), indicating comparable vigilance in both conditions and excluding unspecific effects of the substances on the visual system. Subjects were unable to guess above chance level in which condition they received the active substance.

\section{Discussion}

Research in recent years showed that knowledge about memory systems can be gained by looking at what happens to memory during sleep. For the VDT used in the present experiments, it is known that training related improvements occur only across subsequent periods of sleep (Gais et al., 2000; Stickgold et al., 2000). Less is known about the mechanisms by which sleep achieves this enhancement. By reducing activity of glutamate receptors during post-training sleep with two different glutamate receptor blockers targeting NMDA and AMPA receptors, we show that the consolidation of a visual texture discrimination skill during sleep requires activation of these receptors. The limitation of the learning-related changes to the primary visual cortex, which has been shown in multiple previous studies (Karni and Sagi, 1991; Schoups et al., 2001; Schwartz et al., 2002), allows to reason that particularly activation of glutamatergic synapses in that specific area is required for consolidation during sleep.

The requirement of glutamate receptor activation during consolidation of the VDT fits well into the theoretical framework of memory trace reactivation underlying off-line enhancements in memory. Information in the visual cortex is transmitted via NMDA- and AMPA-type glutamate receptors (Rivadulla et al., 2001). Learning induces within the first 30-60 min after the period of acquisition a series of changes at participating synapses, most importantly, an upregulation of AMPA receptors (Lüscher et al., 2000), followed by a proportional potentiation in NMDA receptor currents (Watt et al., 2004; Perez-Otano and Ehlers,
2005). Later, structural changes to the synapse come into effect, which stabilize potentiation (Lisman, 2003). Thus, encoding leads to an involvement of both types of receptors in mediating long-term plastic changes of the visual cortex after stimulation. In addition, reactivation of previously potentiated synapses could lead to induction of further potentiation at these synapses, thus increasing the effect of learning without additional actual stimulation. Our findings are therefore in accord with the view that glutamate receptors have to be reactivated during the sleepassociated consolidation process in order for permanent improvements to the visual system to occur. The recently proposed concept that sleep improves memory by generally downscaling synaptic strength might be useful in providing an explanation for how this self-amplifying reactivation process is limited and excessive activity is prevented (Tononi and Cirelli, 2006). Global synaptic downscaling and reactivation of specific traces would thus provide two complementary mechanisms that enhance memory during sleep.

Synapse reactivation might serve different purposes. Synaptic potentiation induced during previous learning would decay within hours if it is not stabilized at a later point (Frey and Morris, 1997). Previously, it has been shown that not only induction of long-term potentiation (LTP), but also consolidation of its late phase depends on synaptic stimulation (Fonseca et al., 2006). Because substance administration was timed to coincide with this late phase of LTP, it might have impaired consolidation by blocking necessary synaptic activity. Additionally, stimulusindependent, slow-wave-related cortical activity during sleep will more strongly activate those synapses that have been potentiated than those which have not. This would result in additional "training” during sleep by reactivation of synapses involved previously in learning. A similar model of synaptic re-entry reinforcement requiring postlearning NMDA receptor activation has been described in hippocampus-dependent and hippocampusindependent learning (Shimizu et al., 2000; Wittenberg and Tsien, 2002; Cui et al., 2005).

Several other studies looked also at postlearning administration of glutamatergic antagonists (Riedel et al., 2003). In the auditory cortex of gerbils, NMDA receptor antagonists active during a window of $\sim 60 \mathrm{~min}$ after training, but not during retrieval, of an auditory discrimination task $24 \mathrm{~h}$ later, impaired memory consolidation (Schicknick and Tischmeyer, 2006). In chicks, 10-25 min postlearning administration of NMDA and AMPA receptor blockers resulted in later amnesia for a passive avoidance task (Rickard et al., 1994). A specific form of visual cortex plasticity is expressed in changes of ocular dominance columns after monocular sensory deprivation in young animals. In kittens, postlearning NMDA receptor blockade by ketamine prevented the consolidation of ocular dominance plasticity (Rauschecker et al., 1990), and a similar result was found with the NDMAreceptor antagonist MK-801 [(+)-5-methyl-10,11-dihydro-5H- 
dibenzo [a,d] cyclohepten-5,10-imine maleate] (Daw et al., 1999). A dependency of this form of plasticity on glutamatergic activity on the one hand and sleep on the other has been shown previously (Frank et al., 2001; Ramoa et al., 2001). Previously, it was demonstrated in addition that neuronal activity was necessary during sleep for plastic changes to occur (Jha et al., 2005). Although plasticity in the developing and adult visual cortex are not identical (Carmignoto and Vicini, 1992), our results show that also in the adult human, learning based on very simple processes of synaptic plasticity requires glutamate receptor reactivation during the following hours. Together, there is now reasonable evidence that reactivation of glutamatergic receptors are involved in both induction and consolidation of plasticity in the visual cortex.

\section{References}

Artola A, Singer W (1987) Long-term potentiation and NMDA receptors in rat visual cortex. Nature 330:649-652.

Baughman RW, Gilbert CD (1980) Aspartate and glutamate as possible neurotransmitters of cells in layer 6 of the visual cortex. Nature 287:848-850.

Bear MF (1996) A synaptic basis for memory storage in the cerebral cortex. Proc Natl Acad Sci USA 93:13453-13459.

Boroojerdi B, Battaglia F, Muellbacher W, Cohen LG (2001) Mechanisms underlying rapid experience-dependent plasticity in the human visual cortex. Proc Natl Acad Sci USA 98:14698-14701.

Buzsáki G (1998) Memory consolidation during sleep: a neurophysiological perspective. J Sleep Res 7:17-23.

Carmignoto G, Vicini S (1992) Activity-dependent decrease in NMDA receptor responses during development of the visual cortex. Science 258:1007-1011.

Censor N, Karni A, Sagi D (2006) A link between perceptual learning, adaptation and sleep. Vision Res 46:4071-4074.

Cui Z, Lindl KA, Mei B, Zhang S, Tsien JZ (2005) Requirement of NMDA receptor reactivation for consolidation and storage of nondeclarative taste memory revealed by inducible NR1 knockout. Eur J Neurosci 22:755-763.

Dave AS, Margoliash D (2000) Song replay during sleep and computational rules for sensorimotor vocal learning. Science 290:812-816.

Daw NW, Stein PS, Fox K (1993) The role of NMDA receptors in information processing. Annu Rev Neurosci 16:207-222.

Daw NW, Gordon B, Fox KD, Flavin HJ, Kirsch JD, Beaver CJ, Ji Q, Reid SN, Czepita D (1999) Injection of MK-801 affects ocular dominance shifts more than visual activity. J Neurophysiol 81:204-215.

Dudai Y (2004) The neurobiology of consolidations, or, how stable is the engram? Annu Rev Psychol 55:51-86.

Fonseca R, Nagerl UV, Bonhoeffer T (2006) Neuronal activity determines the protein synthesis dependence of long-term potentiation. Nat Neurosci 9:478-480.

Foster DJ, Wilson MA (2006) Reverse replay of behavioural sequences in hippocampal place cells during the awake state. Nature 440:680-683.

Fox K, Sato H, Daw N (1989) The location and function of NMDA receptors in cat and kitten visual cortex. J Neurosci 9:2443-2454.

Frank MG, Issa NP, Stryker MP (2001) Sleep enhances plasticity in the developing visual cortex. Neuron 30:275-287.

Frey U, Morris RG (1997) Synaptic tagging and long-term potentiation. Nature 385:533-536.

Gais S, Plihal W, Wagner U, Born J (2000) Early sleep triggers memory for early visual discrimination skills. Nat Neurosci 3:1335-1339.

Huber R, Ghilardi MF, Massimini M, Tononi G (2004) Local sleep and learning. Nature 430:78-81.

Ikeda N, Kodama I, Shibata S, Kondo N, Yamada K (1982) Electromechanical effects of caroverine, a new slow-channel blockade, on the SA node cells of rabbit and atrial muscle fibers of rabbit and guinea pig. J Cardiovasc Pharmacol 4:70-75.

Jha SK, Jones BE, Coleman T, Steinmetz N, Law CT, Griffin G, Hawk J, Dabbish N, Kalatsky VA, Frank MG (2005) Sleep-dependent plasticity requires cortical activity. J Neurosci 25:9266-9274.

Kapur S, Seeman P (2002) NMDA receptor antagonists ketamine and PCP have direct effects on the dopamine $\mathrm{D}(2)$ and serotonin
5- $\mathrm{H} T_{(2)}$ receptors-implications for models of schizophrenia. Mol Psychiatry $7: 837-844$.

Karni A, Sagi D (1991) Where practice makes perfect in texture discrimination: evidence for primary visual cortex plasticity. Proc Natl Acad Sci USA 88:4966-4970.

Karni A, Sagi D (1993) The time course of learning a visual skill. Nature 365:250-252.

Karni A, Tanne D, Rubenstein BS, Askenasy JJ, Sagi D (1994) Dependence on REM sleep of overnight improvement of a perceptual skill. Science 265:679-682.

Kirkwood A, Rioult MC, Bear MF (1996) Experience-dependent modification of synaptic plasticity in visual cortex. Nature 381:526-528.

Kumar A, Schliebs R, Bigl V (1994) Postnatal development of NMDA, AMPA, and kainate receptors in individual layers of rat visual cortex and the effect of monocular deprivation. Int J Dev Neurosci 12:31-41.

Lisman J (2003) Long-term potentiation: outstanding questions and attempted synthesis. Philos Trans R Soc Lond B Biol Sci 358:829-842.

Lüscher C, Nicoll RA, Malenka RC, Muller D (2000) Synaptic plasticity and dynamic modulation of the postsynaptic membrane. Nat Neurosci 3:545-550.

Malenka RC, Nicoll RA (1999) Long-term potentiation - a decade of progress? Science 285:1870-1874.

Maquet P (2001) The role of sleep in learning and memory. Science 294:1048-1052.

Maquet P, Laureys S, Peigneux P, Fuchs S, Petiau C, Phillips C, Aerts J, Del Fiore G, Degueldre C, Meulemans T, Luxen A, Franck G, Van Der Linden M, Smith C, Cleeremans A (2000) Experience-dependent changes in cerebral activation during human REM sleep. Nat Neurosci 3:831-836.

Miller KD, Chapman B, Stryker MP (1989) Visual responses in adult cat visual cortex depend on N-methyl-D-aspartate receptors. Proc Natl Acad Sci USA 86:5183-5187.

Mölle M, Marshall L, Gais S, Born J (2004) Learning increases human electroencephalographic coherence during subsequent slow sleep oscillations. Proc Natl Acad Sci USA 101:13963-13968.

Nadasdy Z, Hirase H, Czurko A, Csicsvari J, Buzsáki G (1999) Replay and time compression of recurring spike sequences in the hippocampus. J Neurosci 19:9497-9507.

Oestreicher E, Ehrenberger K, Felix D (2002) Different action of memantine and caroverine on glutamatergic transmission in the mammalian cochlea. Adv Otorhinolaryngol 59:18-25.

Peigneux P, Orban P, Balteau E, Degueldre C, Luxen A, Laureys S, Maquet P (2006) Offline persistence of memory-related cerebral activity during active wakefulness. PLoS Biol 4:e100.

Pennartz CM, Uylings HB, Barnes CA, McNaughton BL (2002) Memory reactivation and consolidation during sleep: from cellular mechanisms to human performance. Prog Brain Res 138:143-166.

Perez-Otano I, Ehlers MD (2005) Homeostatic plasticity and NMDA receptor trafficking. Trends Neurosci 28:229-238.

Quinlan EM, Philpot BD, Huganir RL, Bear MF (1999) Rapid, experiencedependent expression of synaptic NMDA receptors in visual cortex in vivo. Nat Neurosci 2:352-357.

Ramoa AS, Mower AF, Liao D, Jafri SI (2001) Suppression of cortical NMDA receptor function prevents development of orientation selectivity in the primary visual cortex. J Neurosci 21:4299-4309.

Rasch B, Büchel C, Gais S, Born J (2007) Odor cues during slow-wave sleep prompt declarative memory consolidation. Science 315:1426-1429.

Rauschecker JP, Egert U, Kossel A (1990) Effects of NMDA antagonists on developmental plasticity in kitten visual cortex. Int J Dev Neurosci 8:425-435.

Ribeiro S, Gervasoni D, Soares ES, Zhou Y, Lin SC, Pantoja J, Lavine M, Nicolelis MA (2004) Long-lasting novelty-induced neuronal reverberation during slow-save sleep in multiple forebrain areas. PLoS Biol 2:E24.

Rickard NS, Poot AC, Gibbs ME, Ng KT (1994) Both non-NMDA and NMDA glutamate receptors are necessary for memory consolidation in the day-old chick. Behav Neural Biol 62:33-40.

Riedel G, Platt B, Micheau J (2003) Glutamate receptor function in learning and memory. Behav Brain Res 140:1-47.

Rivadulla C, Sharma J, Sur M (2001) Specific roles of NMDA and AMPA receptors in direction-selective and spatial phase-selective responses in visual cortex. J Neurosci 21:1710-1719.

Rumpel S, Hatt H, Gottmann K (1998) Silent synapses in the developing rat 
visual cortex: evidence for postsynaptic expression of synaptic plasticity. J Neurosci 18:8863-8874.

Schicknick H, Tischmeyer W (2006) Consolidation of auditory cortexdependent memory requires $\mathrm{N}$-methyl-d-aspartate receptor activation. Neuropharmacology 50:671-676.

Schoups A, Vogels R, Qian N, Orban G (2001) Practising orientation identification improves orientation coding in V1 neurons. Nature 412:549-553.

Schwartz S, Maquet P, Frith C (2002) Neural correlates of perceptual learning: a functional MRI study of visual texture discrimination. Proc Natl Acad Sci USA 99:17137-17142.

Shimizu E, Tang YP, Rampon C, Tsien JZ (2000) NMDA receptordependent synaptic reinforcement as a crucial process for memory con- solidation. Science 290:1170-1174.

Stickgold R, James L, Hobson JA (2000) Visual discrimination learning requires sleep after training. Nat Neurosci 3:1237-1238.

Tononi G, Cirelli C (2006) Sleep function and synaptic homeostasis. Sleep Med Rev 10:49-62.

Watt AJ, Sjostrom PJ, Hausser M, Nelson SB, Turrigiano GG (2004) A proportional but slower NMDA potentiation follows AMPA potentiation in LTP. Nat Neurosci 7:518-524.

Wilson MA, McNaughton BL (1994) Reactivation of hippocampal ensemble memories during sleep. Science 265:676-679.

Wittenberg GM, Tsien JZ (2002) An emerging molecular and cellular framework for memory processing by the hippocampus. Trends Neurosci 25:501-505. 